\title{
Correction to: Denominational and Gender Differences in Hypertension Among African American Christian Young Adults
}

Paul A. Robbins ${ }^{1}$ (D) Melissa J. Scott ${ }^{1}$ Eugenia Conde ${ }^{1}$ - Yannet Daniel ${ }^{1} \cdot$ William A. Darity Jr. ${ }^{1,2}$. Keisha L. Bentley-Edwards ${ }^{1,3}$

Published online: 6 November 2020

(C) W. Montague Cobb-NMA Health Institute 2020

\section{Correction to: Journal of Racial and Ethnic Health Disparities} https://doi.org/10.1007/s40615-020-00895-4

Readers should note that the "95\% CI" column of estimates for Model 1 was erroneously included under the Model 2 heading in Table 2 in this article as originally published.

The original article has been corrected.

Publisher's Note Springer Nature remains neutral with regard to jurisdictional claims in published maps and institutional affiliations.

The online version of the original article can be found at https://doi.org/ $10.1007 / \mathrm{s} 40615-020-00895-4$

Paul A. Robbins

paul.robbins@duke.edu

1 The Samuel DuBois Cook Center on Social Equity, Duke University, Durham, NC, USA

2 Sanford School of Public Policy, Duke University, Durham, NC, USA

3 Department of Medicine, Duke University, Durham, NC, USA 